\title{
On the Translation of “打” Under the Context Theory: A Case Study of the Coverage of President Xi
}

\author{
Liu Qiaoling \\ College of Foreign Languages, Chongqing University of Posts and Telecommunications, Chongqing, China
}

Email address:

522872513@qq.com

\section{To cite this article:}

Liu Qiaoling. On the Translation of “打” Under the Context Theory: A Case Study of the Coverage of President Xi. History Research. Vol. 7, No. 2, 2019, pp. 49-55. doi: 10.11648/j.history.20190702.14

Received: February 25, 2019; Accepted: April 16, 2019; Published: October 17, 2019

\begin{abstract}
The omnipotent word dă has rich meanings, and is frequently used in the coverage of president Xi. However, the former translation materials concerned with this word were quite outdated and few people have provided the systematic English translation of this word. Under the guidance of Context Theory, the paper analyzes the contexts of the new phrases containing dă and provided the corresponding translation versions on the basis of maintaining the Chinese characteristics to the uttermost. Hopefully the paper will be useful and referential for the translation strategies and techniques of the word dă.
\end{abstract}

Keywords: dă, English Translation, Context Theory, Chinese Characteristics

\section{Introduction}

As a kind of non-literature translation, political essays feature with accuracy, political correctness, timeliness, monosemy, objectivity, integrity, etc [1]. The political translation has long become a headache for translators since it's difficult to balance the correctness and flexibility. Some scholars even discussed how social movement democracies survive under political translation [2]. Li Tao and Xu Fang stated that translation shifts do exist in the translation and attitude towards China becomes less positive while attitude towards other countries less negative in the translation of political discourse from Chinese into English [3]. Such an astonishing finding might have been expected but must have been regarded unreasonable.

The paper will focus on the translation of “打” (dă) phrases selected from political discourse as they were quite frequently delivered by President $\mathrm{Xi}$, ranging from his regional inspection and instruction and nationwide important speeches to international views on international relations. How to help the international community understand the true connotations of these phrases, "enhance the other countries' understanding of China's development, promote the international acknowledgement of the socialist road with Chinese characteristics and improve Chinese culture soft power" [4], are President Xi's earnest expectations towards the translators' responsibilities.
Unfortunately, people were used to regarding translation as a closed process from one text to another, namely a process of literally conversion between two languages, thus unavoidably resulting in culture default. The innovative concepts as "context of situation" and "context of culture" have surpassed the boundary of language itself, and the formerly neglected outside factors were also integrated [5]. Since its introduction, many scholars from home and abroad have conducted researches on and analyses of it either from different perspectives, or by different methods or standards, however, difficulties seem unavoidable due to various and ambiguous concerning aspects. Most of the translators who highly emphasize efficiency and economics seldom apply Context Theory to translation practically. The eight representative “打” phrases, selected from the reports on President Xi hopefully will be systematically analyzed from the perspective of Context Theory so as to illustrate a feasible route in political translation and inspire more scholars to have deeper researches on this field.

\section{The Font Style, Pronunciation and Meaning of "打"}

Chinese is a pictographic language which unifies the font style, pronunciation and meaning of every Chinese character. Chinese characters express people's keen observation and experience of the world. Although the specific font style, 
pronunciation and meaning of each Chinese character has been evolving over time, the fundamental nature that the font style, pronunciation and meaning of each Chinese character are more or less linked with each other remains unchanged. Following is the detailed elaboration of the Chinese character "打", which can help us understand the character more accurately and then translate the "打" phrases more accurately.

\subsection{Font Style}

According to the analysis of Xu Shen in his Shuo Wen Jie Zi (Interpretation of Chinese Characters), the earliest font style of “打” is $\Psi$, which is the combination of the character $\boldsymbol{\Psi}$ (hand, hit, knock) and the character 个 (man, nail). After the simple disassembly of its component and radical, it's possible for a foreigner who never studied Chinese to be inspired to their imagination that the Chinese character "打” is an omnipotent or mighty word- similar to the English word "have" or "make"- which bears rich meanings and frequent usage because people can do a lot of things with hand and tool. Liu Bannong had a comparatively systematic analysis of “打” in his article Dă Yă, in which he elaborated more than 100 word groups of “打” specifically, and he regarded “打” as a $\mathrm{f}^{* *} \mathrm{k}$ word with ambiguous meanings.

Although the ideographic function of the font style has been diminished as Chinese characters inevitably evolve, we can still draw allusion and imagination from many characters. The experts in Fuzzy semantics, after analyzing the features of language fuzziness, pointed out that "it has become a normal situation that people need more and more word groups to express new ideas and new meanings with commonly used words or characters" [6] to echo with the development of people's thinking, the progress of society and the growth of cognition. This is the first reason why the Context Theory is inspirational in translation as word productivity (collocation) and flexibility (cohesive context) are its concerns.

\subsection{Pronunciation}

Though up to now, there's no decisive or definite conclusion about the pronunciation origin of "打", some scholars-after meticulous and precise investigation-believe that “打” is a paronym of “掷”(throw) and “提”(carry, lift). All these words share the central meaning of "striking" and demonstrate similar hand movements-the action by hand by applying a certain medium to be in touch with another object or man, and then impose certain force. They also further analyzed the pronunciation evolution of “打” and came to the conclusion that “打” probably has evolved into two different sounds which, however, share the same etymology [ei] [7].

It is known that Chinese has four tones. The common pronunciation of "打" in Mandarin Chinese is the third tone dă- a relatively tortuous pronunciation process, with tone cut first and rise then. Chinese is a complicated language as some different characters share the same pronunciation at the same time some same Chinese characters share different pronunciations. On the other hand, we have to admit there is an established custom that one specific pronunciation of a Chinese character, no matter how many pronunciations it may bear, might refer to a fixed or constrained meaning. So in this way, the pronunciation and the meaning of a specific Chinese character is interlinked to some extent. However, on the one hand it's not wise to illustrate the semantic meaning of a character merely through its pronunciation. This is the second reason why the Context Theory is conducive in translation because the attempt to imagine the meaning and translation through its pronunciation may be misleading. It again proves the necessity of context analysis in translation.

\subsection{Meaning}

In the Modern Chinese Dictionary, there are 25 interpretations of “打”, 3 sounds, and 4 parts of speech (quantifier, preposition, verb and noun). The Great Chinese Dictionary has listed 29 interpretations. Mr. Cao Xianzhuo wrote an article named Semantic analysis of “打” while he celebrated for the $100^{\text {th }}$ periodical of Lexicographical Studies. This article classified the semantic meanings of “打” into four major ones: 1) original meaning; 2) changed meaning; 3) generic meaning/causative meaning/occurring meaning; and 4) prepositional meaning. Of course, widely and frequently being used, the character "打” was endowed with more new meanings and extended meanings.

Cognitive linguists believe that the major functions of a language are its semantic symbolic function and its communicative function. The semantic symbolic function refers to the possibility that people's cognition towards the outside world can be further symbolized after conceptualization through sound and gesture. Verschueren believes semantic meaning is formed in the adaptability process related to context [8]. Communicative function involves a wider range, such as communication, manipulation, facial expression and social contact, etc. The embodied view, as the foundation of cognitive linguistics system, seeks a more practical and empiric research approach, which agrees with the interaction between translator and environment or context. This is the third reason why Context theory is influential in translation as context is the environment where the semantic meaning differs and occurs accordingly.

\section{Relationship Among Context and Font Style, Pronunciation and Meaning}

As the font style, pronunciation and meaning of “打” have been discussed above, what are their relations with context then? The terminology "context" was firstly put forward by linguist Malinowski in 1923. To be brief, it refers to the different grammatical contexts where the linguistic units appears. Normally speaking, there are two types of context, one is linguistic context and the other is situational context. The former refers to the relevant words/sentences beside the specific word, while the latter refers to the relevant people and 
background of the speech where the specific word appears. To be more specific, it refers to the parties/things involved, the time and space involved, the social environment involved and the subsidiary communicative means (facial expression, gestures and postures) applied, etc.

\subsection{Context and Pronunciation}

As is known to all, the pronunciations of Chinese characters are quite complicated and changeable, even the same phrase may have different pronunciations, thus causing different meanings. Take “好书” as an example, when it is pronounced as "hăo shū", it means good books, while when it is pronounced as "hào shū", it means "be fond of books" or sometime, especially in ancient Chinese prose, it means "be fond of writing/calligraphy". Therefore, a good translator shall never take the words too literally because different context calls for different pronunciation, different meaning and different translation.

\subsection{Context and Font}

The relationship between the font style of Chinese characters and the context is not explicit, but the fact that same Chinese character (of course with totally same font) bears different meanings in different context is known by all. Claire Kramsch believed that the key to understanding language in context is to start not with language, but with context [9]. If the above example of “好书” is not convincing, “负” is another example. “负” means “defeat” in the sentence “胜负 乃兵家常事”; “enjoy” in “久负盛誉”; “burden” in “如释重 负”; “bear or shoulder (responsibility)” in “负责”; “depend on” in “负隅顽抗”; “suffer” in “负伤”; “debt” in “负债”; “minus/smaller than zero" in “负数”; "negative” in “负极” and "betrayal” in “忘恩负义”. Almost all scholars acknowledged the consensus that words generally do not have only one meaning. Su Dingfang summarized Langacker's words as the prescribed meaning of a lexical item must be decided when it's put under the overall linguistic network where it occurred instead of being decided separately [10]. When Chinese characters are used in a wide range and in depth, they are endowed with more different meanings in different situations (not only lingual environment).

\subsection{Context and Meaning}

Chen Zhi'an and Wen $\mathrm{Xu}$ described the six features of context: 1) certainty, which refers to the fixed context once there is verbal communication; 2) relativity, which refers to the constantly changing factors in the context; 3) hierarchy, which refers to numerous general contexts and specific context; 4) transitivity; 5) symmetry; and 6) reflexivity, which refers to the critical thinking that discourse itself is its own context [11].

With so many features, context indeed exert a great influence on the meaning of Chinese characters in the following aspects: 1) context singularizes meaning; 2) context concretizes meaning; 3) context adds temporary meaning; 4) context decides the meaning to be chosen. Translation is a language communicative activity which happens in the specific linguistic, situational and cultural context. Since context restricts and influences meaning, translation should be subject to context in order to convey the surface meaning, deep meaning and the possible ellipsis meaning.

\section{Current Studies of "打”}

\subsection{Meaning of “ $f J$ ”}

The mighty Chinese character “打” shares abundant meanings. Before we analyze the translation of the eight chosen "打" phrases, a brief picture of its meanings can be enlightening.

A few meanings are listed hereunder for your reference: “打” means (1) Crash an object with hands or tools, such as “打鼓” (beat a drum); (2) Be broken because of crash, such as “鸡飞 蛋打” (the hen has flown away and the eggs in the coop are broken); (3) hit or beat, such as “打架” (fight with sb); (4) the activity through which you get along with sb, such as “打交 道”; (5) construct or build, such as “打坝”; (6) make or manufacture, such as “打刀”; (7) stir, such as “打匀鸡蛋”; (8) bundle, such as “打包”; (10) wave, such as “打毛衣”; (11) paint, draw, such as “打蜡”; (12) uphold, such as “打伞”; (13) thunder, such as “打雷”; (14) spoon up or buy, such as “打水”, “打酱油”; (15) catch or hunt, such as “打猎”; (16) cut or chop, such as “打草”; (17) figure out or decide, such as “打主意”; (18) do or engage in, such as “打杂”; (19) play games, such as “打牌”; (20) certain body languages, such as “打哈欠”; (21) adopt certain ways or engage into, such as “打官司”; (22) remove, eliminate or kill, such as “打虫”. One might be fascinated with the meanings of “打” even if we only listed a few above due to limited space.

\subsection{Current Researches on the Translation of “打”}

How strange it is that such an important word receives little attention from the Chinese academia, not to mention the western academia. The quantity of the research papers on the translation of “打” is so small that only less than 20 papers can be found from CNKI $[12,13]$. Besides, the translations of “打” are a little bit narrow-minded as the translators ignored the analysis of the corresponding context. Ross Beveridge suggested that "translation is about the negotiation of meanings, the roles actors play and their relations to each other and the objects around them", and importantly, "the process of translation aims to reveal how objectives are often mediated not merely by the negotiations which take place with humans but also by the performances of technologies and nature" [14]. Context is reliable but also scalable. In addition, the previous studies focus on outdated “打” phrases which need to be updated as both the translation practices and translation researches should keep pace with the times. The paper only lists eight phrases containing “打” which were extracted from the political discourse by president $\mathrm{Xi}$, and hopefully the paper can inspire more researches on this important Chinese character. 


\section{Context Theory}

The Functionalist school represented by John Firth (1890-1960) has developed the Context Theory of Bronislaw Malinowski (1884-1942) by emphasizing the comprehensive study of language not only from the perspective of language itself but also its social function and situational context.

Thanks to these scholars, translation studies explored the new research domain and contributed themselves to broadening the connotation and denotation of "context". On the one hand, context contains all factors like morphology, semantics and pragmatics, and all the orderly and disorderly, inevitable and incidental factors like the speaker, syntactic form, relevance, referent, essential significance, etc [15], and on the other hand, it is context that "has unified external reference with internal reference" [16].

Context Theory has manifested clearly and vividly that any context element is meaningless when it exists independently; and any element is lively and significant when it is in the specific and historical context where it correlates with other elements [15]. Therefore, "a topic can become a kind of activity under the context of language game", accordingly, "the comprehension of a sentence means the comprehension of a language" [17]. And the relation between meaning and context is that the meaning of a word becomes simplified and concrete because of the limitation of context, and that context can supplement the omitted meaning and produce temporary meaning of the words, phrases and sentences [18]. There is no wonder that translators should consider the context so as to comprehend the meaning more clearly and correctly.

\section{Translation of Chinese Political Discourse}

Mr. Huang Youyi has put forward three "close" principles for C-E translation: 1) being close to the actual situation of China's development; 2) being close to the target readers' demands of Chinese information, 3) and being close to the target readers' way of thinking [19]. These three "close" principles are applicable to the translation of Chinese Political Discourse as well, however, if we want to move further, another "close" principle- being close to the Chinese culturecan never be neglected.

Professor Wei Qingguang believes SWOT analysis method is conducive to the translation organizations who are eager to figure out a better translation strategy. SWOT model is applicable to translation studies [20] although few scholars attempted to do so. In his book, Wei also designed an analysis framework for the translation strategies (see table 1) [21].

Table 1. SWOT Analysis of the Language Strategies of Chinese Culture Going Out Initiative.

\begin{tabular}{|c|c|c|}
\hline Environmental factors & $\begin{array}{l}\text { Internal strength }(\mathrm{S}) \text { : standard management, } \\
\text { sound reputation, abundant capital and resources. }\end{array}$ & $\begin{array}{l}\text { Internal weakness (W): language expression } \\
\text { in translation does not suit for the language } \\
\text { habit of target countries or regions. }\end{array}$ \\
\hline $\begin{array}{l}\text { Opportunities }(\mathrm{O}) \text { : supported by national policy, } \\
\text { funded by the government, and Chinese culture } \\
\text { is highly expected by other countries. }\end{array}$ & $\begin{array}{l}\text { SO strategy: MAX (S)-MAX (O), may be the best } \\
\text { strategy, by which the internal strength and external } \\
\text { opportunities can be exploited. }\end{array}$ & $\begin{array}{l}\text { WO strategy: MIN (W)-MAX }(\mathrm{O}) \text { fully make } \\
\text { use of all possible opportunities can overcome } \\
\text { weakness. }\end{array}$ \\
\hline $\begin{array}{l}\text { Threats }(\mathrm{T}) \text { : communication habit and styles of } \\
\text { the target countries. }\end{array}$ & $\begin{array}{l}\text { ST strategy: MAX (S)-MIN (T) make use of the } \\
\text { internal strength and get rid of the threating factors. }\end{array}$ & $\begin{array}{l}\text { WT strategy: MIN (W)-MIN (T) overcome } \\
\text { weakness and meet the threats }\end{array}$ \\
\hline
\end{tabular}

(S (strength), W (weakness), O (opportunity), T (threat))

As for the language strategies, professor Wei believes that we must convert the weakness of the Organization and the external threats by adjusting the translation strategies to cater to the communication habits and styles of foreign countries in order to introduce Chinese culture to the world more effectively [21].

It is obvious that the translation strategies advocated by Professor Wei are similar to the three "close" principles by Huang Youyi. Both of them emphasize on the target readers' recognition and the translation effect, however, the principle of "being close to Chinese culture" has been ignored for long. Consequently, Chinese words go out but Chinese culture stays at home.

When we check the officially translated text by the Compilation and Translation Bureau of the CPC Central Committee or the reports by New York Times, "being close to Chinese culture" has indeed been highly emphasized. However, "being close to Chinese culture" sounds too abstract for the translator to find the balance. Therefore, we should look at the principle dialectically. On the one hand, the suggestion by some experts that we should adopt literal translation or zero translation simply for maintaining Chinese culture is irrational; on the other hand, translating the political discourse mechanically should be criticized. The balance itself is not balance anymore if the balance is fixed. The balance itself is balance again if the balance is mixed. That's why all translation principles only offer you ways to take in translation but never limit your choices. That's the essence of Context Theory as it reminds you there are a lot of visible and invisible factors to be considered in translation but you have to adjust your translation strategies accordingly in different situations.

\section{Context Analyses of "打" Phrases and Translation}

Different from writers, the purpose of translators is to reconstruct the scenes of the original text in the target text while they are influenced by the culture and social cognition in the source language and the target language as well [22]. From the perspective of the Context Theory, we will analyze the corresponding contexts of the eight “打” phrases and provide the translation respectively. Translation is credible without the 
consideration of the context.

\section{1. “不能打我的旗号办任何事, 否则别怪我六亲不认”}

The sentence is extracted from president Xi's speech when he was in office in Fujian Province years ago. President Xi adheres to his good family traditions and wants to warn his family members and relatives to be strict with themselves by this sentence.

The key words of this sentence-“打旗号”, “六亲不认” -should be translated properly. The phrase “打旗号” cannot be translated literally into "wigwag", which may confuse the readers. Actually its real meaning is as follows: doing something in the name of somebody; flaunting the good relationship with somebody in front of others; or make use of somebody as the shield to facilitate something". The literal meaning of “六亲不认” is being unkind or inhuman to all of one's relatives, which has two translations in the dictionary as "repudiate all of one's relatives" and "disown all of one's relatives". It is usually regarded as a derogatory term. However, obviously the real meaning of “六亲不认” in this sentence differs from its commonly used meaning. It doesn't refer to all relatives but only the relatives who make use of the position/relationship to influence somebody or something. So translating the phrase word by word is not acceptable.

Trial translation: I shall disown any of my relatives if anyone of them attempts to do anything in my name.

\section{2. “全面深化改革零敲碎打调整不行”}

Since all industries developed disproportionately in China, and it's highly recommended to have reforms covering every industry. Besides, according to the past experience, the reforms in some certain industries were too formalized and superficial. The national policy of "comprehensively deepening reform", highlighted by President $\mathrm{Xi}$, was born at the right time. It means conducting the reform of all domains comprehensively and coordinately. Such magnificent reform requires overall and systematic planning and improvement.

The phrase “零敲碎打” means “do something discontinuously, which was explained as "do something bit by bit" or "do something in bits and pieces" in the dictionary. However, the English idiom "in dribs and drabs" can be used here to explain something that is discontinuous and lacks of integrated planning.

Trial translation: Fragmented adjustments in dribs and drabs are unworkable for deepening all-round reforms.

\section{3. “习近平访美首站将主打经贸”}

At the invitation of US President Barack Obama, President Xi embarked on a state visit to the US in 2015 for the first time since becoming president. At that time before President Xi's departure, the visit was highlighted with the great hopes and achievements and some expectations depicted on crucial topics on climate change, energy resources, cyber security, etc. Indeed, they had in-depth exchange of viewing with each other.
This sentence is extracted from a report published by China daily during President Xi's visit. It is quite easy. “主 打” means forging, creating or introducing something specially.

Trial translation: President Xi puts trade and economic issues at the top of his diplomatic agenda during his first US stop.

\section{4. “中国高铁在美国打“翻身仗””}

China's high speed trains have achieved great success domestically, but how to create its international sales network worries not only the heads of producers but also our president. In the September of 2015, when president Xi visited the USA, he boosted not only the sales volume of domestic airplanes but also the Chinese high speed trains which have encountered multiple difficulties and challenges in going globally.

The phrase “打翻身仗” means getting out of troubles or disadvantages through efforts, the synonym of which is converting defeat into victory. In the dictionary, the corresponding translation of this phrase is the phrase "turn around". If we use "turn around", the sense of humor and the sense of image will be greatly diminished. A more vivid and livelier phrase "turn the tables" may be better to explain the complete reversal of the former bad circumstances.

Trial translation: China's high-speed rail has turned the tables in the USA.

\section{5. “谁为习近平外访“打前站””}

Mr. Meng Jianzhu, the special envoy of president Xi, visited the USA before president Xi's state visit. The phrase “打前站” originally means someone goes to the proposed destination to attend to the food and accommodation for other partners. The corresponding translation in the dictionary is as follows: 1 ) act as an advance party; 2) make advance arrangements/preparations for $\mathrm{sb}$. The report on Meng Jianzhu's visit to the USA is available on the Website-Mr. Meng traveled to Washington as President $\mathrm{Xi}$ Jinping's Special Envoy to discuss cyber security and other issues in advance of President Xi's State Visit. The report can be used for reference.

Trial translation: Who will be in advance of President Xi's State Visit?

\section{6. “安倍将遭习近平当面敲打?”}

This sentence was extracted from a short video made by Phoenix Focus News on $17^{\text {th }}$, Oct, 2014 [23], when Japan's home affairs were unsatisfactory. So the Japanese leader wanted to relieve its domestic pressure and distract the public attention to the outside. So Shinzo Abe tried to adopt some diplomatic strategies to break the diplomatic deadlock or ice, however, Japan was unexpectedly doing something threatening the world at the same time.

The original meaning of “敲打” is "beating or hitting”, which of course is not appropriate to express international relations. The phrase “敲打” has another meaning of reminding someone verbally or denouncing or declining 
someone politely and subtly. Informal wording "tell somebody where to get off" means "to make it clear to somebody that you will no longer accept their bad behavior". This may be perfectly used here to show standpoints as well as to reduce conflicts.

Trial translation: Will President Xi tell Shinzo Abe where to get off?

\section{7. “打铁还需自身硬”}

This sentence is extracted from chapter 11 of the series of important speeches by president $\mathrm{Xi}$ Jinping in which he instructed the whole Chinese Communist Party members to strengthen the party discipline. Hereby, we can easily draw the conclusion that “自身” (self) refers to the Chinese Communist Party.

There are many ready translations which were listed below.

1. To be turned into iron, the metal itself must be strong. (by the interpreter on site)

2. To forge iron, you need a strong hammer. (by the Daily Telegraph)

3. To forge iron, one must be strong. (by the $\mathrm{CNN}$ and the New York Times)

4. To address these problems, we must first of all conduct ourselves honorably. (by the Xinhua News Agency)

Different translations differ in their understanding of “自身” (self). Zhihu, the Chinese Quora has a detailed analysis as follows [24].

Actually what follows the sentence is “绣花要得手绵巧” (embroidering requires for skilled hands). The sentence coherence will help us find the most appropriate translation.

The above translations are different in the comprehension of “自身”.

1. To be turned into iron, the metal itself must be strong. In this sentence, “自身” was regarded as "the metal itself".

2. To forge iron, you need a strong hammer. In this sentence, “自身” was regarded as "a strong hammer".

3. To forge iron, one must be strong. In this sentence, “自身” was regarded as "one" who forges the iron.

4. To address these problems, we must first of all conduct ourselves honorably. In this sentence, “自身” was regarded as "we". The translation is good as the translator adopted Domestication strategy and successfully brought the text to the target readers. It is right and unquestionable. But as we stated before, the principle of "being close to Chinese culture" is necessary. So the following analyses will ignore this sentence.

If we put the sentence in the linguistic context, the following sentence is “绣花要得手绵巧” (embroidering requires for skilled hands), in which the subject is "hand". Coherently, the subject of the former sentence “打铁还需自 身硬” cannot mean "the metal being forged", or the "hammer", rather it should be the person who forges the iron.

Appropriate translation: To forge iron, one must be strong.

\section{8. “两岸是打断骨头连着筇的兄弟”}

When President Xi met the leader of Taiwan Mr. Ma
Ying-jeou in Singapore, he emphasized that the cross-strait compatriots are one family. President Xi also quoted an old saying that blood is thicker than water. The proverb “打断骨 头连着筋" is used to describe the deep love between family members and close family ties even if there is contradiction or conflict. Since the exact sources of these versions are not available, we can only list the translation version hereunder. Personally speaking, the first and the last translation containing "compatriots" seem to express the meaning more clearly. Because the translation itself can provide us the context.

Translations for reference:

1) Bones may be broken, but they are not split, because we are compatriots.

2) Bones may be broken, but not sinews.

3) Brothers connected by flesh even if our bones are broken-The Economist.

4) Bones may be broken but not the sinews, because we are fellow compatriots.

\section{Conclusion}

Chinese character is the perfect combination of sound, font and meaning. Same font may share different sounds, and same font may share different meaning even if the sound is totally the same. Thus, the paper has demonstrated that the translation of the mighty word "打" should be rendered under the guidance of the Context Theory. As to the translation principles, "being close to Chinese culture" should be kept in mind besides the three "close" principle proposed by Mr. Huang Youyi. As there is no definite strategy applicable to all translations of political discourse, the translators are requested to find a balance under the corresponding context. The Chinese characters are so extensive and profound that a simple word “打” has so many different meanings in different situations. Therefore, context should be specifically highlighted in order to break down cultural barriers and realize effective and successful C-E translation. All in all, the C-E translation should be readers-oriented, function-oriented, source text-abided, and source context-abided so that the true Chinese culture can be understood properly and China's international image can be upgraded extensively.

\section{References}

[1] Wang Xiaoping. On the Difficulty of Translating Chinese Political Documents into English and its Solutions [J]. Shandong Foreign Language Teaching Journal, 2016 (5): 109-112.

[2] Leondar-Wright, Betsy. Political translation: how social movement democracies survive. Social Movement Studies [J]. 2019, 18 (3): 385-386.

[3] Li Tao, Xu Fang. Re-appraising self and other in the English translation of contemporary Chinese political discourse [J]. Discourse Context \& Media. 2018, 25: 106-113. 
[4] Huang Youyi, Huang Changqi, et al. Highlighting C-E translation of political documents and strengthening the construction of China's international discourse system [J]. Chinese Translators Journal, 2014 (3): 5.

[5] Malinowski $\mathrm{B}$. The problem of meaning in primitive languages [A]. OGDEN C K, RICHARDS I A. The Meaning of Meaning [C]. London: Routledge \& Kegan Paul, 1923.

[6] Wang Yin. Semantic Theory and Language Teaching [M]. Second Edition. Shanghai: Shanghai Foreign Language Education Press, 2014: 275.

[7] Zhang Hongmei. On the Phonetic and Semantic Origin of the word 打 [J]. Journal of Fuling Teachers College. 2005, 21 (3): $62-65$.

[8] Verschuerne, J. Understanding pragmatics [M]. London: Edward Arnold (Publishers) Ltd, 1999: 147-151.

[9] Claire Kramsch. Context and Culture in Language Teaching [M]. Oxford: Oxford University Press. 1993: 34.

[10] Su Dingfang. An introduction to Cognitive Semantics [M]. Shanghai: Shanghai Foreign Language Education Press, 2008: 77.

[11] Chen Zhi'an, Wen Xu. On the features and taxonomy of context [J]. Journal of Foreign Languages, 1997 (4): 22-26.

[12] Hu Muyi. On the English translation of the Chinese character “打” [J]. Shandong Foreign Language Teaching, 1988 (1): 56-59.

[13] Yu Xiaomei, Wang Shaohua. Translation of "Dahupaiying" and Its Translatological Implication [J]. Journal of Fuyang Normal University (Social Science). 2015 (3): 31-35.
[14] Ross Beveridge. A Politics of Inevitability [M]. VS Verlag für Sozialwissenschaften, 2012: 93, 94.

[15] Guo Guichun, He Tianping. Study on the Western Modern Pragmatics Philosophy [M]. Beijing: Science Press, 2006: 158, 193.

[16] Guo Guichun. On context [J]. Philosophical Researches, 1997 (4): 46-52.

[17] Hans Johaun Glock. A Wittgenstein Dictionary. Oxford: Blackwell Publishers Inc., 1996. 89

[18] Wang Yuanxin. Linguistics [M]. Beijing: China Minzu University Press, 2009: 216.

[19] Huang Youyi. Adhering to the three "close" principles and dealing with the problems in C-E translation properly $[\mathrm{J}]$. Chinese Translators Journal. 2004, 25 (6): 27-28.

[20] Kong Lingcui, Liu Qiaoling. Translation is also marketing: The study of translation strategies for International Communication based on SWOT analysis [J]. Foreign Language and Literature. 2018, 34 (1): 127-133.

[21] Wei Qingguang. Study on social operation of China's translation activities since 1978 [M]. Beijing: China Social Sciences Press, 2014: 31.

[22] He Wei, Zhao Changling. Model of Cognitive Functional Context in Translation [J]. Foreign Language and Literature. 2016, 32 (5): 112-117.

[23] http://v.ifeng.com/v/news/ablkq/index.shtml\#019da16b-5136$44 \mathrm{~d} 2-92 \mathrm{~d} 1-3 \mathrm{e} 09 \mathrm{~b} 562 \mathrm{f} 86 \mathrm{e}$

[24] http://www.zhihu.com/question/20751660 